\title{
A case of castration-resistant prostate cancer with liver metastases achieved a complete response by docetaxel chemotherapy
}

\author{
Suguru Shirotake, Yuta Umezawa, Takashi Okabe, Go Kaneko, Kent Kanao, Koshiro Nishimoto, \\ Masafumi Oyama \\ Department of Uro-Oncology, Saitama Medical University International Medical Center, Saitama, Japan \\ Correspondence to: Suguru Shirotake, MD, PhD. 1397-1 Yamane, Hidaka, Saitama 350-1298, Japan. Email: ss6001@5931.saitama-med.ac.jp.
}

\begin{abstract}
Castration-resistant prostate cancer (CRPC) patients with liver metastases have an extremely poor prognosis. Herein, we report a rare patient who achieved a complete response by docetaxel chemotherapy for this aggressive disease. A 67-year-old Japanese male diagnosed with local prostate cancer [initial prostate specific antigen (PSA) of $10.3 \mathrm{ng} / \mathrm{mL}$, a highest Gleason score of eight] received radical prostatectomy (RP) followed by salvage radiotherapy for PSA recurrence without distant metastases. After four years, androgen deprivation therapy was commenced for both local recurrence and elevated PSA. After a further four years, despite good control of PSA $(1.2 \mathrm{ng} / \mathrm{mL})$, other clinical findings including radiographic images revealed CRPC with multiple liver metastases. Ten cycles of docetaxel chemotherapy achieved a complete response for more than five years. In conclusion, even if a patient has CRPC with liver metastases, early diagnostic imaging irrespective of the PSA level may provide a better response to early docetaxel chemotherapy.
\end{abstract}

Keywords: Castration-resistant prostate cancer (CRPC); liver metastasis; docetaxel chemotherapy

Submitted Aug 24, 2019. Accepted for publication Jan 06, 2020.

doi: $10.21037 /$ tau.2020.01.20

View this article at: http://dx.doi.org/10.21037/tau.2020.01.20

\section{Introduction}

The presence of visceral disease in patients with metastatic castration-resistant prostate cancer (mCRPC) has been identified as one of the important prognostic factors for overall survival (OS) (1-3). A meta-analysis of phase III trials (4-12) of a total of about 9,000 patients with mCRPC who received docetaxel treatment revealed that visceral disease was present in $20.8 \%$ (e.g., lung $9.1 \%$, liver $8.6 \%$ ), and that the median OS time in patients with liver metastases (13.5 months) was significantly shorter than those with bone (21.3 months) or lung metastases (19.4 months) (3).

Although the androgen receptor (AR) axis targeted therapies (ARAT), including abiraterone acetate and enzalutamide, have been commonly used for patients with mCRPC, docetaxel treatment can be considered for patients suspected of ARAT resistance or with visceral metastatic disease (13). However, even when a prostate specific antigen (PSA) response ( $45 \%$ to $64 \%$ ) or radiological response
(12\% to $28 \%)$ are observed by docetaxel treatment, the progression survival time is typically at a median of 6 to 8 months $(5,9)$.

We herein present a rare patient with CRPC and liver metastases who achieved a complete response for more than five years following docetaxel treatment.

\section{Case presentation}

A 67-year-old Japanese male (SIMC-Uro \#542: a unique, non-sequential patient control number in the Department of Uro-Oncology, Saitama Medical University International Medical Center) had an elevated serum PSA of $10.3 \mathrm{ng} / \mathrm{mL}$ without symptoms at a check-up examination in 2005 . The patient had no significant medical history. At another hospital, a prostate biopsy revealed a prostate adenocarcinoma with a highest Gleason score of eight (4+4). Radiographic imaging showed no evidence of local 


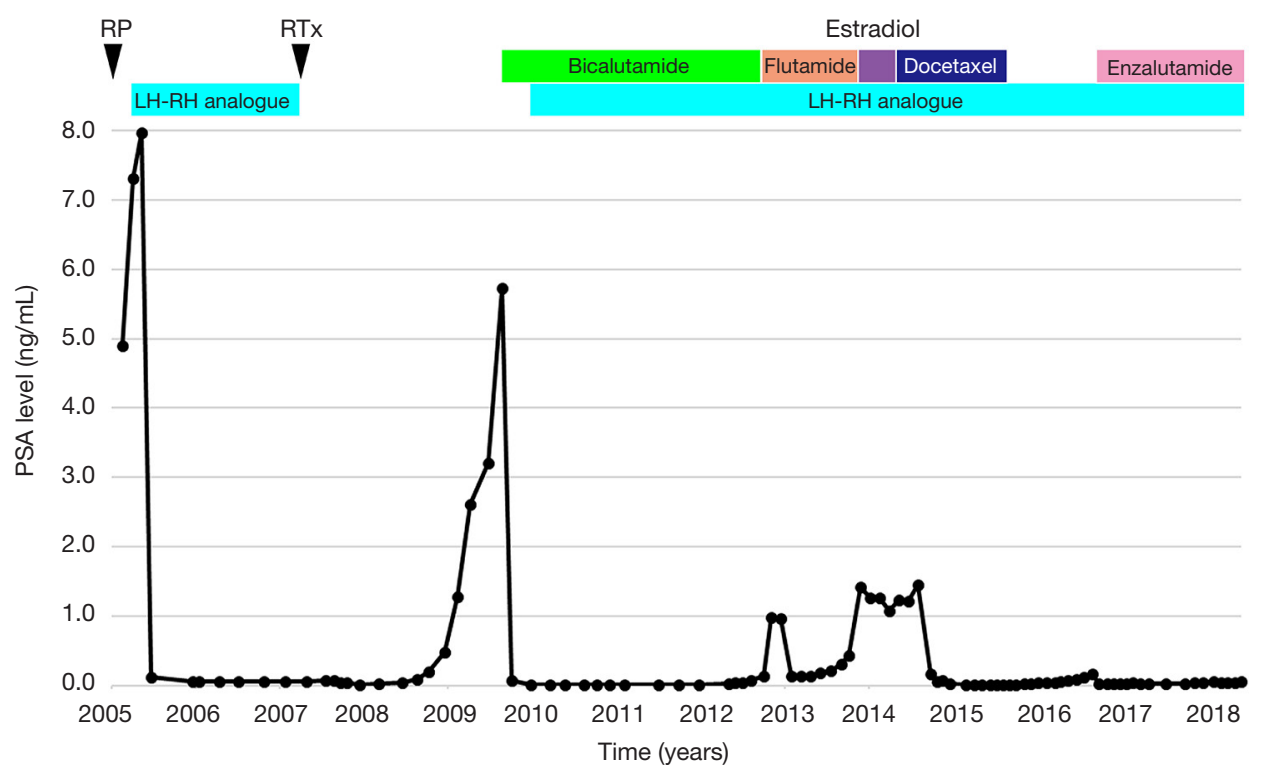

Figure 1 PSA changes from the initial treatment. RP, radical prostatectomy; RTx, radiotherapy; LH-RH, luteinizing hormone-releasing hormone; PSA, prostate specific antigen.

progression or distant metastases. A luteinizing hormonereleasing hormone (LH-RH) analogue was initiated by the attending physician (details unknown), and then he was referred to another hospital for radical treatment.

In February 2005, his preoperative PSA level was $4.90 \mathrm{ng} / \mathrm{mL}$, and a radical prostatectomy $(\mathrm{RP})$ with pelvic lymphadenectomy was performed. The pathological diagnosis was adenocarcinoma with a highest Gleason score of eight (4+4), pT2N0, and a negative resected margin. The changes in PSA level and treatments after RP are shown in Figure 1. LH-RH analogue treatment (leuprorelin $3.75 \mathrm{mg}$ monthly) was re-initiated due to a postoperative PSA nadir of $7.31 \mathrm{ng} / \mathrm{mL}$ at 39 days after RP, and PSA of $0.11 \mathrm{ng} / \mathrm{mL}$ at 118 days after RP.

He was referred to our institution in 2007 with the aim of continuing treatment for elevated PSA after RP. External irradiation (total $60 \mathrm{~Gy} / 30$ fractions, RTx in Figure 1) performed after confirming that there were no distant metastases, and then the LH-RH analogue was withdrawn. Unfortunately, his PSA level rapidly increased from February 2009 (PSA 1.279 ng/mL). Radiographic imaging (Figure 2) in September 2009 showed no evidence of distant metastases (Figure $2 A, C$ ), but an unidentified region was found between the bladder and rectum, which suggested local recurrence in a part of the remaining seminal vesicle (* in Figure 2B). As PSA increased to $5.739 \mathrm{ng} / \mathrm{mL}$, maximum androgen blockade was commenced with the addition of bicalutamide ( $80 \mathrm{mg} /$ day) and an LH-RH analogue (goserelin $10.8 \mathrm{mg} 3$-monthly) from February 2010, resulting in an immediate decrease in the PSA level. Subsequently, due to a lack of PSA response, flutamide $(250 \mathrm{mg} /$ day) was replaced with bicalutamide in October 2012 (PSA $0.139 \mathrm{ng} / \mathrm{mL}$ ), and estradiol ( $1.5 \mathrm{mg} /$ day) was replaced with flutamide in November 2013 (PSA $1.421 \mathrm{ng} / \mathrm{mL}$ ). Almost six months after starting estradiol administration, he unexpectedly visited our outpatient center with a complaint of anorexia, and he had a PSA of $1.237 \mathrm{ng} / \mathrm{mL}$ at that time. There were no abnormal laboratory data. However, computed tomography (CT) imaging showed multiple nodules with surrounding enhancement in the liver and in the prostate bed, and a newly sclerotic lesion in the right pubis (Figure 2D,E,F). Gastrointestinal endoscopy and assessment of tumor markers including CEA and CA199 revealed normal findings, suggesting that multiple liver metastases, bone metastasis and local recurrence originated from prostate cancer. The serum levels of neuron-specific enolase (NSE) and pro-gastrin-releasing peptide (pro-GRP) were not examined.

Subsequently, docetaxel chemotherapy $\left(75 \mathrm{mg} / \mathrm{m}^{2}\right.$ every 3 to 4 weeks, depending on the patient's condition) with prednisolone $(10 \mathrm{mg} /$ day $)$ was initiated for metastatic mCRPC in August 2014. The major complaint of anorexia gradually improved, and his PSA level also decreased (Figure 1). CT imaging showed a marked reduction of liver 

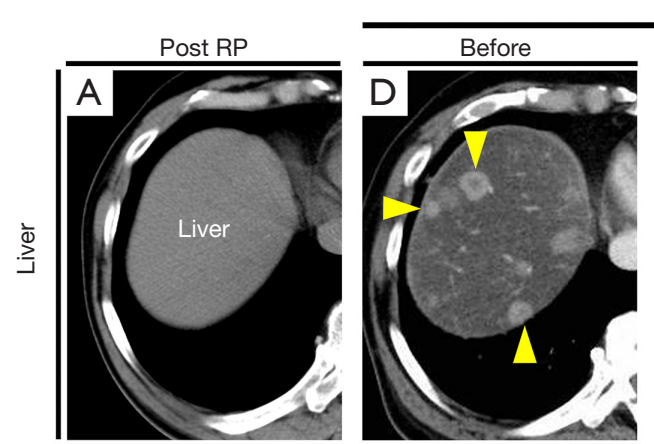

Docetaxel treatment
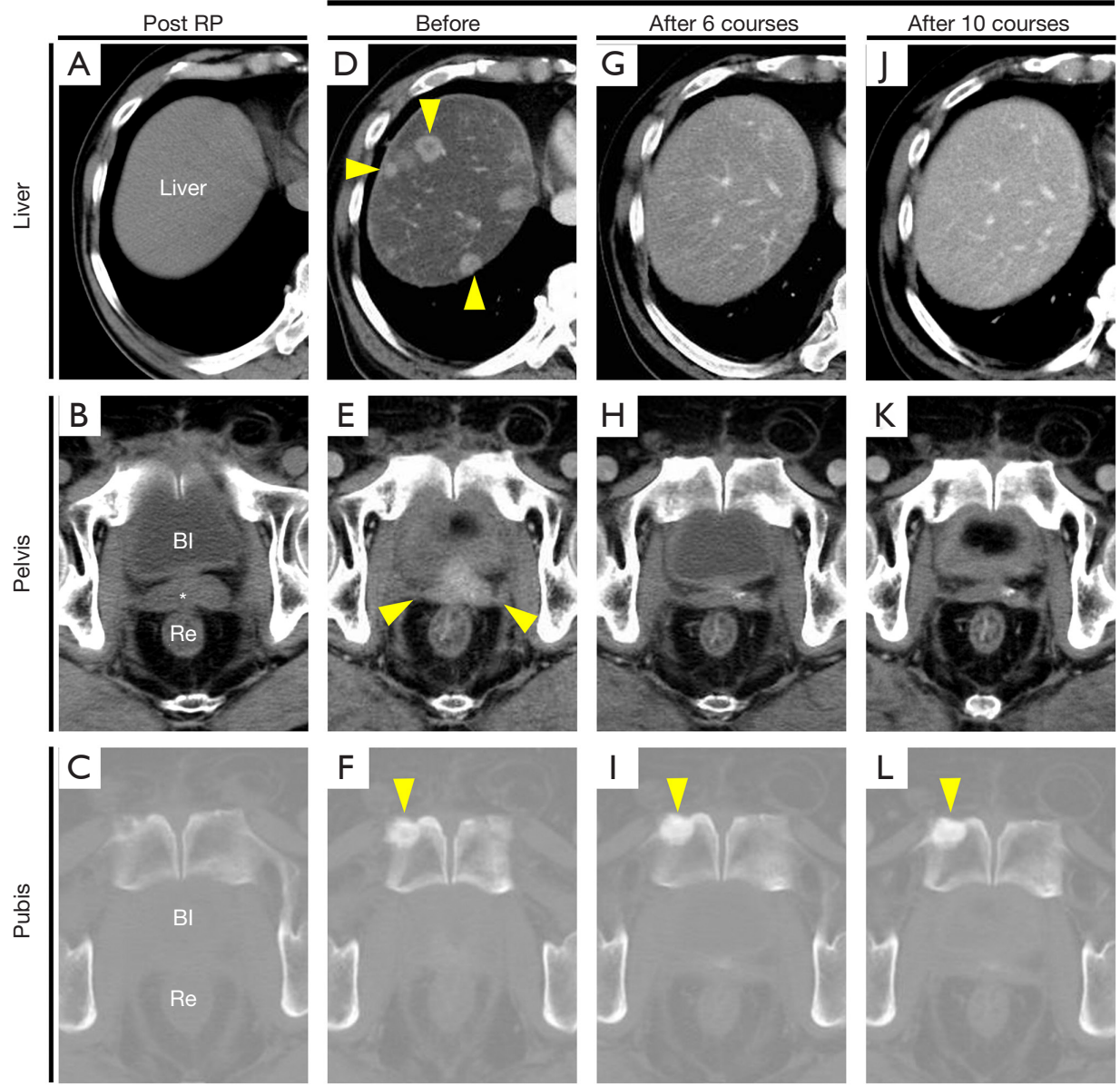

Figure 2 Abdominal and pelvic computed tomography imaging. (A,B,C) At post-radical prostatectomy; (D,E,F) before docetaxel treatment; (G,H,I,J,K,L) after docetaxel treatment. Yellow arrow heads show disease lesions. *, a part of the remaining seminal vesicle; RP, radical prostatectomy; Bl, bladder; Re, rectum.

metastases and local recurrence after 6 and 10 cycles of docetaxel chemotherapy (Figure $2 G, H, \mathcal{F}, K$ ). However, the sclerotic lesion in the pubis remained (Figure 2I,L). A total of 10 cycles of docetaxel chemotherapy were terminated and both blood (e.g., PSA) and radiographic examinations (e.g., CT and bone scintigraphy) were routinely performed.

His PSA level gradually increased after the last docetaxel chemotherapy (a PSA of $0.170 \mathrm{ng} / \mathrm{mL}$ in August 2016), and radiographic imaging did not show any new metastatic lesions, including in the liver. Enzalutamide was administered at an initial dose of $80 \mathrm{mg} /$ day due to his general condition. His PSA level immediately decreased, and there were no abnormal radiographic findings except for the sclerotic lesion persisting in the right pubis. Ultimately, a complete response for more than five years was achieved with docetaxel chemotherapy for CRPC with multiple liver metastases.

\section{Discussion}

We encountered an extremely rare case in which a complete response to CRPC with multiple liver metastases was achieved by docetaxel chemotherapy. Of note, the intriguing issue in this case was the early radiographic diagnosis of multiple metastases in a non-metastatic CRPC patient despite a low and stable PSA level.

Irrespective of the presence of metastases, CRPC patients have been recommended to be monitored by physical examinations and laboratory tests including PSA every 3 to 6 months, as well as undergoing regular imaging tests, 
including bone scans and CT or MRI $(14,15)$. Nevertheless, many physicians rely on PSA and physical examinations as the principal measures of response and progression, and imaging is often reserved until the appearance of symptoms or PSA progression. The post hoc analysis of the PREVAIL study has not been validated and could result in delayed detection of disease progression if it occurs without a rise in PSA (16). Indeed, this study showed progression in $24.5 \%$ of patients on enzalutamide without any PSA progression, and that $34.3 \%$ of patients with visceral metastases had nonrising PSA levels (16). These results suggest that a disease monitoring strategy needs not only PSA measurements, but also imaging, to more accurately evaluate disease progression.

Recently, ${ }^{68} \mathrm{Ga}$-PSMA-PET using radiolabeled prostatespecific membrane antigen (PSMA) ligands, has achieved higher specificity and sensitivity in the detection of metastases compared to standard imaging (CT, MRI and bone scintigraphy), resulting in improved detection of metastatic lesions at low serum PSA levels (17). However, it should be noted that CRPC with neuroendocrine transdifferentiation could represent loss of PSMA-expression of liver metastases in progressive disease (18). Further studies will identify the optimal modalities and imaging frequency, especially for patients with non-metastatic CRPC.

CRPC tumors associated with a lack of PSA progression, such as the present case, may have become less reliant on AR for their growth and may indicate the need for chemotherapy or treatment using non-AR targeting strategies. Namely, patients with good performance status who are able to tolerate chemotherapy, are suspected to be ARAT treatment resistance (e.g., prior response to $\mathrm{ADT}<1$ year), are symptomatic or have visceral metastatic disease, and should be considered for docetaxel treatment, and subsequent cabazitaxel treatment (13). However, patients with CRPC should generally be considered to have $\mathrm{PCa}$ variant components, including neuroendocrine prostate cancer, which presents with loss of PSA expression, symptomatic disease and visceral disease. These PCa variants may have a high likelihood of resistance to both ARAT therapy and taxane-based chemotherapy; therefore, patients with these aggressive diseases should be considered for the platinum-based chemotherapy (19). The present patient continues to receive enzalutamide for both the slight increase in PSA and the remaining pubic sclerotic lesion after docetaxel treatment, and has shown a complete response to mCRPC. In the future, if this patient develops new visceral metastases, we will select docetaxel re-challenge treatment followed by cabazitaxel treatment, considering platinum-based chemotherapy for a PCa variant disease.

In conclusion, this successful case suggests that even if a CRPC patient has visceral metastases including in the liver, early diagnostic imaging irrespective of PSA level may lead to early initiation of docetaxel chemotherapy, resulting in a favorable clinical outcome.

\section{Acknowledgments}

Funding: None.

\section{Footnote}

Conflicts of Interest: All authors have completed the ICMJE uniform disclosure form (available at http://dx.doi. org/10.21037/tau.2020.01.20). The authors have no conflicts of interest to declare.

Ethical Statement: The authors are accountable for all aspects of the work in ensuring that questions related to the accuracy or integrity of any part of the work are appropriately investigated and resolved. Written informed consent was obtained from the patient for publication of this manuscript and any accompanying images.

Open Access Statement: This is an Open Access article distributed in accordance with the Creative Commons Attribution-NonCommercial-NoDerivs 4.0 International License (CC BY-NC-ND 4.0), which permits the noncommercial replication and distribution of the article with the strict proviso that no changes or edits are made and the original work is properly cited (including links to both the formal publication through the relevant DOI and the license). See: https://creativecommons.org/licenses/by-nc$\mathrm{nd} / 4.0 \%$.

\section{References}

1. Armstrong AJ, Garrett-Mayer ES, Yang YC, et al. A contemporary prognostic nomogram for men with hormone-refractory metastatic prostate cancer: a TAX327 study analysis. Clin Cancer Res 2007;13:6396-403.

2. Halabi S, Lin CY, Kelly WK, et al. Updated prognostic model for predicting overall survival in first-line chemotherapy for patients with metastatic castrationresistant prostate cancer. J Clin Oncol 2014;32:671-7.

3. Halabi S, Kelly WK, Ma H, et al. Meta-Analysis 
Evaluating the Impact of Site of Metastasis on Overall Survival in Men With Castration-Resistant Prostate Cancer. J Clin Oncol 2016;34:1652-9.

4. Petrylak DP, Tangen CM, Hussain MH, et al. Docetaxel and estramustine compared with mitoxantrone and prednisone for advanced refractory prostate cancer. $\mathrm{N}$ Engl J Med 2004;351:1513-20.

5. Tannock IF, de Wit R, Berry WR, et al. Docetaxel plus prednisone or mitoxantrone plus prednisone for advanced prostate cancer. N Engl J Med 2004;351:1502-12.

6. Kelly WK, Halabi S, Carducci M, et al. Randomized, double-blind, placebo-controlled phase III trial comparing docetaxel and prednisone with or without bevacizumab in men with metastatic castration-resistant prostate cancer: CALGB 90401. J Clin Oncol 2012;30:1534-40.

7. Fizazi K, Higano CS, Nelson JB, et al. Phase III, randomized, placebo-controlled study of docetaxel in combination with zibotentan in patients with metastatic castration-resistant prostate cancer. J Clin Oncol 2013;31:1740-7.

8. Quinn DI, Tangen CM, Hussain M, et al. Docetaxel and atrasentan versus docetaxel and placebo for men with advanced castration-resistant prostate cancer (SWOG S0421): a randomised phase 3 trial. Lancet Oncol 2013;14:893-900.

9. Tannock IF, Fizazi K, Ivanov S, et al. Aflibercept versus placebo in combination with docetaxel and prednisone for treatment of men with metastatic castration-resistant prostate cancer (VENICE): a phase 3, double-blind randomised trial. Lancet Oncol 2013;14:760-8.

10. Araujo JC, Trudel GC, Saad F, et al. Docetaxel and dasatinib or placebo in men with metastatic castrationresistant prostate cancer (READY): a randomised, doubleblind phase 3 trial. Lancet Oncol 2013;14:1307-16.

11. Petrylak DP, Vogelzang NJ, Budnik N, et al. Docetaxel

Cite this article as: Shirotake S, Umezawa Y, Okabe T, Kaneko G, Kanao K, Nishimoto K, Oyama M. A case of castrationresistant prostate cancer with liver metastases achieved a complete response by docetaxel chemotherapy. Transl Androl Urol 2020;9(2):819-823. doi: 10.21037/tau.2020.01.20 and prednisone with or without lenalidomide in chemotherapy-naive patients with metastatic castrationresistant prostate cancer (MAINSAIL): a randomised, double-blind, placebo-controlled phase 3 trial. Lancet Oncol 2015;16:417-25.

12. Chi KN, Higano CS, Blumenstein B, et al. Custirsen in combination with docetaxel and prednisone for patients with metastatic castration-resistant prostate cancer (SYNERGY trial): a phase 3, multicentre, open-label, randomised trial. Lancet Oncol 2017;18:473-85.

13. Chi K, Hotte SJ, Joshua AM, et al. Treatment of mCRPC in the AR-axis-targeted therapy-resistant state. Ann Oncol 2015;26:2044-56.

14. Scher HI, Morris MJ, Stadler WM, et al. Trial Design and Objectives for Castration-Resistant Prostate Cancer: Updated Recommendations From the Prostate Cancer Clinical Trials Working Group 3. J Clin Oncol 2016;34:1402-18.

15. Mohler JL, Antonarakis ES, Armstrong AJ, et al. Prostate Cancer, Version 2.2019, NCCN Clinical Practice Guidelines in Oncology. J Natl Compr Canc Netw 2019;17:479-505.

16. Bryce AH, Alumkal JJ, Armstrong A, et al. Radiographic progression with nonrising PSA in metastatic castrationresistant prostate cancer: post hoc analysis of PREVAIL. Prostate Cancer Prostatic Dis 2017;20:221-7.

17. Damjanovic J, Janssen JC, Prasad V, et al. (68)Ga-PSMA$\mathrm{PET} / \mathrm{CT}$ for the evaluation of liver metastases in patients with prostate cancer. Cancer Imaging 2019;19:37.

18. Rauscher I, Maurer T, Fendler WP, et al. (68)Ga-PSMA ligand PET/CT in patients with prostate cancer: How we review and report. Cancer Imaging 2016;16:14.

19. Aparicio AM, Harzstark AL, Corn PG, et al. Platinumbased chemotherapy for variant castrate-resistant prostate cancer. Clin Cancer Res 2013;19:3621-30. 